\title{
The scientists of today: revisiting Leonardo in a global environment
}

\author{
Sylvia Daunert
}

Published online: 21 November 2008

(C) Springer-Verlag 2008

Historically, scientists have come from all kinds of backgrounds, and beliefs. In all cultures and civilizations, from the early tribal times until today, scientists have occupied prominent or, at the very least, notorious positions within their communities. One could argue that scientists are as diverse as the innumerable "philosopher-scientists" in ancient Greece, to the alchemists from the Medieval ages, to the co-existing collaborating Jewish, Moorish, and Christian scientists from the "Golden Age" in Spain, and the incredibly productive inventors and scientists from the Italian Renaissance. A common thread that unites scientists of all times is their curiosity and quest for knowledge. By and large, this breed of human beings is tenacious, inquisitive, imaginative, and inventive. There is no doubt that scientists have been and are the cornerstones of human progress. Throughout history, scientists have been instrumental in contributing to the advancement of human society by either discovering or understanding basic scientific dogmas, and by inventing new methods or instruments. Certain periods have been more productive than others with respect to the impact of scientific progress. For instance, take the Renaissance, perhaps one of the most productive and amazing periods with regard not only to science but also to the arts, the humanities, and society. Fantastic scientists and engineers roamed the lands and made such key discoveries as Galileo's concept of inertia, establishment of modern astronomy, and implementing the scientific method. My favorite scientist of the time though has to be the incomparable Leonardo da Vinci. Leonardo embodied the spirit of the Renaissance at its fullest; he was the type of man who one day would invent a helicopter and another

S. Daunert $(\bowtie)$

Department of Chemistry, College of Arts and Sciences,

University of Kentucky,

Lexington, KY 40506-0055, USA

e-mail: daunert@uky.edu day would describe a type of surgery, while taking minimal time off from science to paint such icons as the "Last Supper" and "La Gioconda". Leonardo was a man of broad scientific interests, which he demonstrated continuously by lecturing and writing about his different discoveries. He was a truly multidisciplinary scientist working across disciplines. For example, Leonardo, commissioned by Cesare Borgia, designed the clever and beautiful canal harbor of Cesenatico in the Adriatic Sea in 1502, a feat of engineering problem-solving and aesthetic beauty. Another interesting aspect of Leonardo is that in a sense he kept reinventing himself by periodically focusing his interests on different issues. In doing so, he was able to maintain the admiration of the Florentine society, and more importantly have the Duque di Medici as his benefactor during most of his life.

It has taken us three centuries to embrace the concept of diversity in science.

The 19th and the early 20th Centuries brought times of high specialization in science, and little diversity. The belief at the time was that unless a scientist was highly specialized he/she would not be able to make progress in a meaningful manner. The consequence is that we had a very split scientific community with chemists, physicists, biologists, engineers, and physicians, for example, working in their own corners and never crossing the street to converse with each other. Even within chemistry, there was sort of a "snobbish" sentiment that would result in little interaction between members of the traditional disciplines, namely, analytical, physical, organic, and inorganic chemistry. Despite this division, we cannot forget that the 20th Century had a myriad of incredible scientists who were able to think beyond a traditional discipline and discovered milestone after milestone. For example, the curiosity of Linus Pauling (Nobel Prize in Chemistry in 1954 and Nobel Peace Prize in 1962) allowed him to venture away from his first training in chemical engineering to physical/inorganic 
chemistry and later on to make contributions in the fields of molecular biology and biochemistry. Likewise, William Lipscomb (Nobel Prize in Chemistry, 1976), who first studied chemistry, continued his education in physics, and returned to inorganic chemistry under the influence of Pauling, made his more important contributions in a field far from his rooted discipline, namely enzymology. In a sense, it is thus disappointing, that the conventional awards structure within the professional societies still recognizes divisional excellence rather than encourages multidisciplinary endeavors. Very few of the awards given by these professional societies, such as the American Chemical Society, recognize multidisciplinarity. If anything, they tend to recognize subdisciplines within traditional divisions.

Nowadays, we are finally understanding that we are living in a diverse and global society, a fact that is ever true in science. Boundaries do not exist as they did five decades ago, and scientists rooted in a discipline are eager to learn from their colleagues trained in disciplines other than theirs, and to apply the gained knowledge to problems that otherwise could not be solved successfully. Moreover, a welcome trend in scientific education is to ensure that students at the undergraduate and graduate level get a "taste" of scientific diversity by exposing them through courses, seminars, workshops, and research to disciplines beyond their chosen field of study. The National Science Foundation of the United States (NSF) recognized the importance of multidisciplinary education, and to address the issue in 1997 created The Integrative Graduate Education and Research Traineeship (IGERT) program to meet the challenges of educating US PhD scientists, engineers, in interdisciplinary fields, capable of working effectively in a diverse, globally engaged science and engineering workforce (http://www.nsf.gov/crssprgm/igert/ intro.jsp). Currently there are 125 IGERT programs in such varied topics as stem cells, biological device interfaces, nano/micro-technology and life sciences, environmental ecology, etc. Moreover, similar programs are also in place in Europe. European counterparts to the NSF have similar programs in EU countries, e.g., the Graduiertenkollegs of the Deutsche Forschungsgemeinschaft (http://www.dfg.de/ en/research_funding/coordinated_programmes/research training groups/index.html). The result is the creation of a first wave of a new breed of scientists who are capable of thinking in many dimensions and outside the canons of "traditional" disciplines. The pay-off is still to be realized but, in my opinion, will be bountiful.

Hand-in-hand with regard to importance, diversity in science shares the spotlight with globalization and the impact of science on society. Globalization of economic and social issues in some parts of the world is rapidly becoming a reality. The foremost example is the European Union with its common currency and laws. Undoubtedly a success, following in its steps, Argentina and Brazil just announced the future implementation of common currency for both countries with the aim of expanding it to the rest of the South American nations. It is the first step toward the creation of a real global socio-economic union in South America. The scientists of today and of tomorrow need to be able to function in such a global environment, and for that we need to prepare them adequately. Programs of mobility within the European Union for students at the graduate and postgraduate levels (e.g., the current Socrates and Leonardo da Vinci programs) have been very successful and are rapidly accomplishing their goal of training scientists who can work and collaborate in an efficient manner within the EU country boundaries. No doubt that the "free movement" of scientists across borders has contributed to the creation of new programs, and has impacted research and discovery in the $\mathrm{EU}$ in an astoundingly positive manner. Collaborations among Universities, research institutions, and even industry that twenty years ago seemed unlikely, nowadays are commonplace within the EU under the auspices of such programs as EUREKA, COST, etc. There is no question that scientists of the EU have set an example on how to be global and how to contribute to the advancement of science by working in a symbiotic manner. The NSF also has a series of international programs in place that foster collaboration between researchers in the USA and abroad. More notably, newer initiatives focusing on globalization have aimed at providing international educational/research opportunities for undergraduate, graduate, and postgraduate students (e.g., the Developing Global Scientists and Engineers program, International Research Experiences for Students or IRES, and the Doctoral Dissertation Enhancement Projects or DDEP). In my opinion, the EU and NSF programs are models that should be followed. A recent example of international cooperation is the creation of the particle accelerator at The European Organization for Nuclear Research, CERN, where an estimated 10,000 people from 60 countries were involved in designing and building the accelerator and particle detectors. Along with scientists from the 20 European members of the CERN, scientists, engineers, students, and technicians from 94 US universities and laboratories supported by the EU, US Department of Energy Office of Science, and the National Science Foundation are part of this project.

Scientists not only need to take into account the impact of their discoveries on society, but also tailor their work to solve problems that society encounters now and anticipate the ones that will emerge. Climate change is an example of a problem affecting humankind and all aspects of society. Scientists, and chemists, in particular, need to take this issue to heart and work together to find multidisciplinary solutions. I, for one, have faith in our new generation of 
chemists solving this and other problems of importance, such as human hunger, finding a cure for cancer and for genetic diseases, and the energy crisis. We cannot be passive about these issues; we need to be proactive and tackle them immediately in a concerted manner, both from the scientific viewpoint and the social-global one. As Johann Wolfgang von Goethe said "Es ist nicht genug, zu wissen, man muss auch anwenden; es ist nicht genug, zu wollen, man muss auch tun." . Nowadays, the human race certainly does not have the time or luxury to sit around and let things happen. We now need to address the scientific and the social-global concerns that humans face by working together globally and integrating current knowledge stemming from diverse areas of science and technology.

Analytical and Bioanalytical Chemistry publishes articles from researchers from all corners of the globe on such diverse topics as nanotechnology, bionanotechnology, microfabrication, surface chemistry, art preservation, and genetically modified foods, just to name a few. We encourage young investigators to highlight their research in our journal by periodically dedicating special issues to them, and rewarding a young author of an outstanding research paper with the yearly "Best Paper Award". The journal produces special issues concentrating on timely areas of research, and touches upon topics and news of interest to chemists in the editorials and special features. The "analytical challenge" provides a means of self-testing the knowledge of readers in an enjoyable manner, while the book reviews give practical reports on recently published specialty and textbooks relevant to our readership.

The current issue of Analytical and Bioanalytical Chemistry features examples of both multidisciplinarity and globality. Celebrating the 7th Anniversary of the Journal, this issue showcases current research by the members of our International Advisory Board. We are grateful to our Board members for their truly excellent participation, making this issue the largest collection of invited papers ever published in this journal. We are also grateful for their most valuable input and sage advice. The diverse geographical and scientific background of the Board members is an asset to our journal. All of us, the members of the International Advisory Board, the editors in France, Germany, Italy, Japan, Spain, and the USA, the managing editor, and the members of the editorial office in Heidelberg, are committed to moving the journal forward and to increasing its reach and readership by selecting features and topics that are current and timely. As always, we warmly welcome input and suggestions from the readers and authors of Analytical and Bioanalytical Chemistry, whose contributions have helped our journal become a global modern multidisciplinary chemistry publication.

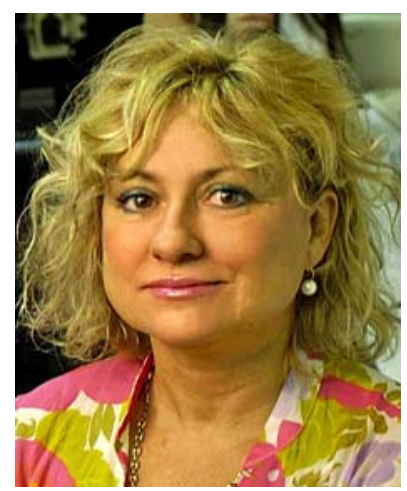

\section{Sylvia Daunert}

is the Gill Eminent Professor of Analytical and Biological Chemistry, the 2004-2005 Distinguished Professor from the College of Arts and Sciences at the University of Kentucky, and a 2005-2006 University of Kentucky Research Professor. Dr Daunert's research interests lie in the area of bioanalytical chemistry, at the interface between analytical chemistry, molecular biology, and bioengineering. More specifically, her group employs recombinant DNA technology to design new molecular diagnostic tools and biosensors based on genetically engineered proteins and cells for applications in biomedical and environmental fields. Additionally, the research of her group focuses on the design of sensing arrays for the detection of molecules in small volumes and microfluidic platforms, and in the development of smart biomaterials for responsive drug delivery systems. Dr Daunert has served as Editor of Analytical and Bioanalytical Chemistry since its inception in 2001.

\footnotetext{
${ }^{1}$ English Translation: "Knowing is not enough; we must apply it. Being willing is not enough, we must take action."
} 